\title{
Incidence of gastric carcinoma at King Faisal Specialist Hospital- Jeddah Saudi Arabia: a hospital-based study
}

\author{
Raha Alahmadi' $^{*}$, Osman Hamour ${ }^{*}$, H. Al-Enizi ${ }^{2}$ and A. Tashkandi ${ }^{1}$ \\ ${ }^{1}$ Department of Surgery, King Faisal Specialist Hospital and Research Center (Gen Org) Jeddah Branch, Saudi Arabia \\ ${ }^{2}$ Research Center, King Faisal Specialist Hospital and Research Center (Gen Org) Jeddah Branch, Saudi Arabia
}

\begin{abstract}
Stomach cancer is the fifth most common cancer worldwide, and the third leading cause of death from cancer making up $7 \%$ of cases and $9 \%$ of deaths. The present study aimed at providing an image of the incidence of gastric carcinoma, with all its epidemiological and pathological characteristics including their trends during the last decade in a tertiary care hospital in the western region of Saudi Arabia. After obtaining an Institutional Review Board approval to conduct this retrospective study in King Faisal Specialist Hospital, a tertiary care institution in the western part of Saudi Arabia; the charts of 76 consecutive patients diagnosed with gastric cancer between January 2002 and 2013, were abstracted. Forty seven patients were included in the study. The charts were reviewed for demographic data, clinical data, diagnostic tools, endoscopic location of the tumour, size of the tumour, the imaging performed, the pathological features, the treatment given, and the final outcome. Forty seven patients were included in the study, thirty three (70\%) of them were males, and the mean age of all patients was $57.55 \pm 19.24$ years. Forty three of the patients $(91.5 \%)$ had intestinal type, thirty two $(68.1 \%)$ had poorly differentiated cancer. Fourteen out of the 47 had palliative chemotherapy and twenty two patients out of 47 underwent surgery with curative intent. Two out of the 22 who had surgery received neoadjuvant chemotherapy, while only 7 had adjuvant chemotherapy. Fifteen out of the 22 who underwent surgery died, seven out of the 22 had a recurrence. Median overall survival for the 47 patients was 7 months, and the overall survival for the 22 patients who underwent surgery was 24 months. The median overall survival for the 25 patients, who did not undergo surgery was 2 months (Log rank, p-value $=0.0005$ ). Gastric cancer is among the deadliest forms of cancer in Saudi Arabia, with gradual increase in the incidence over the last decade, but its incidence still considered low in comparison to other countries worldwide. The outcome of our patients was poor, and we believe this is due to late presentation in the majority of our patients. Surgery is the mainstay of treatment for resectable gastric cancer, while perioperative and adjuvant chemotherapy, as well as chemoradiation, can improve outcome of resectable gastric cancer with extended lymph node dissection. Further research is required to study the epidemiology and the pathological features and the mode of presentation of gastric cancer in the Kingdom of Saudi Arabia.
\end{abstract}

\section{Introduction}

Globally stomach cancer is the fifth most common cancer and the third leading cause of death from cancer making up $7 \%$ of cases and $9 \%$ of deaths [1]. The worldwide incidence of gastric cancer has declined rapidly over the recent few decades [2-6], despite the decline, the absolute number of new cases per year is increasing, mainly due to aging in the world population [7]. The incidence of gastric cancer worldwide in both genders in 2012 according to world health organization (WHO) is 952,000 cases $(631,000$ in men, and 320,000 in women) [8]. This represents a substantive change since the very first estimates in 1975 when stomach cancer was the most common neoplasm [8]. More than $70 \%$ of cases $(677,000$ cases) occur in developing countries, and half the world total occurs in Eastern Asia (mainly in China) [8].

As the stomach cancer represents the third leading cause of death worldwide, the highest estimated mortality rates are in Eastern Asia (24 per 100,000 in men, 9.8 per 100,000 in women), the lowest in Northern America (2.8 and 1.5, respectively) [8]. Although the incidence of distal stomach cancer has decreased, still the incidence of proximal stomach cancer cardia and gastroesophageal junction (GEJ) is increasing [9]. More than two-thirds of patients diagnosed with gastric cancer will have unresectable disease [10], due to the late presentation. Although the prognosis has improved over the last two decades due to the advances in surgical technique, and multimodality therapy, surgical resection remains the mainstay of treatment of resectable gastric cancer [11].

The high mortality rate reflects the prevalence of advanced disease at presentation and relatively aggressive biology. According to data from the National Cancer Institute Surveillance, Epidemiology, and End Results (SEER) Program, the five-year survival for patients with gastric cancer improved only modestly over the last 50 years, from 12 percent in the years 1950 to 1954 , to 22 percent during the period 1996 to 2003 [12]. The incidence of gastric cancer in Saudi Arabia in 2012 in both genders as per the WHO is 3.14 (3.84 in men, and 2.41 in women), while the mortality is 2.68 in both genders (3.29 in men, and 2.05 in women) [8]. A total of 291 cases of stomach cancer were diagnosed in 2010 in the Kingdom of Saudi Arabia according to the Saudi Cancer Registry data which reflects gradual increase in the incidence over the last decade in both males and females. Stomach cancer ranked the eleventh among the male and female population. It accounts for $2.9 \%$ of all diagnosed cancers, with the highest Age Specific Rate (ASR) being in Najran region at 5.2/100,000, followed by AlJouf region at $4.7 / 100,000$, Riyadh region at 4.2/100,000, Eastern and Qassim regions at 3.2/100,000 for each [13].

Correspondence to: Osman Hamour and Raha Alahmadi, Department of Surgery, King Faisal Specialist Hospital and Research Center (Gen Org) Jeddah Branch, Saudi Arabia, E-mail: osmanahamour@gmail.com, ohamour@kfshrc.edu.sa,ral-ahmadi21@kfshrc.edu.sa

Key words: gastric cancer, incidence surgery, neoadjuvant, adjuvant therapy

Received: March 13, 2016; Accepted: March 29, 2016; Published: April 01, 2016 


\section{Materials and methods}

\section{Patients}

After obtaining an Institutional Review Board approval to conduct this retrospective study in King Faisal Specialist Hospital, a tertiary care institution in the western part of Saudi Arabia; the charts of 76 consecutive patients diagnosed with gastric cancer between January 2002 and 2013, were abstracted. The charts were reviewed for demographic data, clinical data, diagnostic tools, endoscopic location of the tumour and its size, the imaging performed, the pathological features, the treatment given, and the outcome.

Patients were staged according to the criteria of the AJCC 7th edition. The collected data was entered in Case Review Form (CRF) for analysis. All patients were referred for multidisciplinary team (MDT) meeting for discussion and decision making about the best treatment strategy. The MDT consists of medical and radiation oncology, radiology, pathology, an upper GI surgeon and other general surgeons. After the preoperative assessment, the patients were divided into two groups: those with loco-regional disease who are potentially resectable (stage I to III) and those with systemic disease (stage IV) with local or distant involvement. Patients with advanced stage IV disease are usually referred to palliative therapy depending on their symptoms and performance status as discussed by the MDT.

\section{Statistical analyses}

Statistical analyses were performed by using SPSS version 20 . Numerical data were presented as mean $+/$ - standard deviation (SD) (For normally distributed data); median and range (For not normally distributed data). Nominal data were expressed by percentages. Kaplan-Meier curve was performed to describe the survivals and the comparison between the median estimates was assessed by log-rank test. P-values $<0.05$ were considered to be statistically significant.

\section{Results}

Out of 76 patients twenty nine cases were excluded due to the fact that the patients presented to our hospital only for second opinion and no treatment was given because of advanced disease. The total number of the patients who were diagnosed with gastric carcinoma and included in the study was 47 patients. The highest and lowest numbers of the cases over the years were $8(17 \%)$ in $2012,1(2 \%)$ in $2003,1(2 \%)$ in 2005 and $1(2 \%)$ in 2006 as shown in (Table 1). Thirty three (70\%) were male patients. The ratio of female to male was $1: 2.3$ and the mean age of all was $57.55 \pm 19.24$ years. The mean age of the male patients was $57.87 \pm 3.50$ and for female patients was $57.25 \pm 4.42(\mathrm{t}=0.10, \mathrm{df}=45$, $p$-value $=0.91)$. Most of the cases had their tumor in the body 25(53\%) (Table 1). Forty three of the patients $(91.5 \%)$ had intestinal type and 4 (8.5\%) had diffuse type. Thirty two $(68.1 \%)$ were poorly differentiated and $15(31.9 \%)$ were moderately differentiated. Signet ring features were present in 26 (55.3\%). The median for carcino-embryonic antigen (CEA) level for 7 patients at the diagnosis was $4.9 \mathrm{ug} / \mathrm{L}$. While test for human epidermal growth factor receptor-2 (HER2) expression was only done in 9 patients and it was negative. Fourteen out of the $47 \mathrm{had}$ palliative chemotherapy and twenty two patients out of 47 underwent surgery with curative intent (Figure 1).

\section{Patients underwent surgery}

Two out of the 22 patients received neoadjuvant chemotherapy. While only 7 had adjuvant chemotherapy. Ten out of the 22 had their tumor in the antrum (Table 1). Those who underwent distal
Table 1. Patients characteristics.

\begin{tabular}{|c|c|}
\hline Characteristics & N (\%) \\
\hline \multicolumn{2}{|l|}{ Gender } \\
\hline Males & $33(70)$ \\
\hline Females & $14(30)$ \\
\hline \multicolumn{2}{|l|}{ Incidence of cases over the years } \\
\hline 2002 & $6(13)$ \\
\hline 2003 & $1(2)$ \\
\hline 2004 & $3(6)$ \\
\hline 2005 & $1(2)$ \\
\hline 2006 & $1(2)$ \\
\hline 2007 & $4(9)$ \\
\hline 2008 & $3(6)$ \\
\hline 2009 & 2(4) \\
\hline 2010 & $7(15)$ \\
\hline 2011 & $6(13)$ \\
\hline 2012 & $8(17)$ \\
\hline 2013 & $5(11)$ \\
\hline \multicolumn{2}{|l|}{ Tumor site (For all cases \#47) } \\
\hline \multicolumn{2}{|l|}{ Body } \\
\hline Antrum and pyloric area & $25(53)$ \\
\hline Fundus and cardia & $18(38)$ \\
\hline AJCC staging (For all cases \#47) & $4(9)$ \\
\hline Stage IV & $28(60)$ \\
\hline Stage III & $10(21)$ \\
\hline Stage II & $7(15)$ \\
\hline Stage I & $2(4)$ \\
\hline \multicolumn{2}{|l|}{ Tumor site (For surgery group \#22) } \\
\hline & $10(46)$ \\
\hline Antrum & $8(36)$ \\
\hline Body & $4(18)$ \\
\hline Fundus & \\
\hline \multicolumn{2}{|l|}{ AJCC staging (For surgery group \#22) } \\
\hline 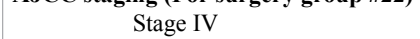 & $3(14)$ \\
\hline Stage III & $10(46)$ \\
\hline Stage II & $7(32)$ \\
\hline Stage I & $2(9)$ \\
\hline \multicolumn{2}{|l|}{ TNM Staging (For surgery group \#22) } \\
\hline $\mathrm{T} 4$ & $11(50)$ \\
\hline $\mathrm{T} 3$ & $4(18)$ \\
\hline $\mathrm{T} 2$ & $6(27)$ \\
\hline $\mathrm{T} 1$ & $1(5)$ \\
\hline N3 & $7(32)$ \\
\hline $\mathrm{N} 2$ & $4(18)$ \\
\hline N1 & $6(27)$ \\
\hline No & $5(23)$ \\
\hline M1 & $3(14)$ \\
\hline M0 & $19(86)$ \\
\hline
\end{tabular}

gastrectomy were eight, while 8 had near total gastrectomy and 6 had total gastrectomy. Thirteen had D1 lymphadenectomy and 9 had D2 lymphadenectomy. The mean follow up in months was $20.75 \pm 15.24$. Twenty had intestinal type and only 2 had diffuse type. Twelve patients were poorly differentiated and 10 were moderately differentiated. The signet ring feature was present in 9 out of the 22. Eleven had positive lympho-vascular invasion (LVI), which is found to be higher in T4 patients $(n=7),(63.6 \%)$. The mean of the positive $\mathrm{LN}$ was $6.45 \pm 6.74$ and the mean of the total $\mathrm{LN}$ removed was $13.72 \pm 7.87$. The mean of tumor size was $6.23 \pm 4.6$. Twenty one had negative surgical margins.

Eleven (50\%) patients had T4, seven (31.8\%) had N3 and three (13.6\%) had M1, all of them were diagnosed intraoperatively, two of them in the liver, and one in the ovaries (Table 1).Those who had their tumor at antrum had the highest number of $\mathrm{N} 3(\mathrm{n}=4,18.2 \%)$. On the other hand, those whose tumor size was 6 or above had more N3 $(n=5,22.7 \%)$ than those with a size 6 or below. While those who had signet ring features had higher N3 $(n=4,18.2 \%)$ and those who hadn't had signet ring features, had higher N1 $(n=4,18.2 \%)$. Those who had 


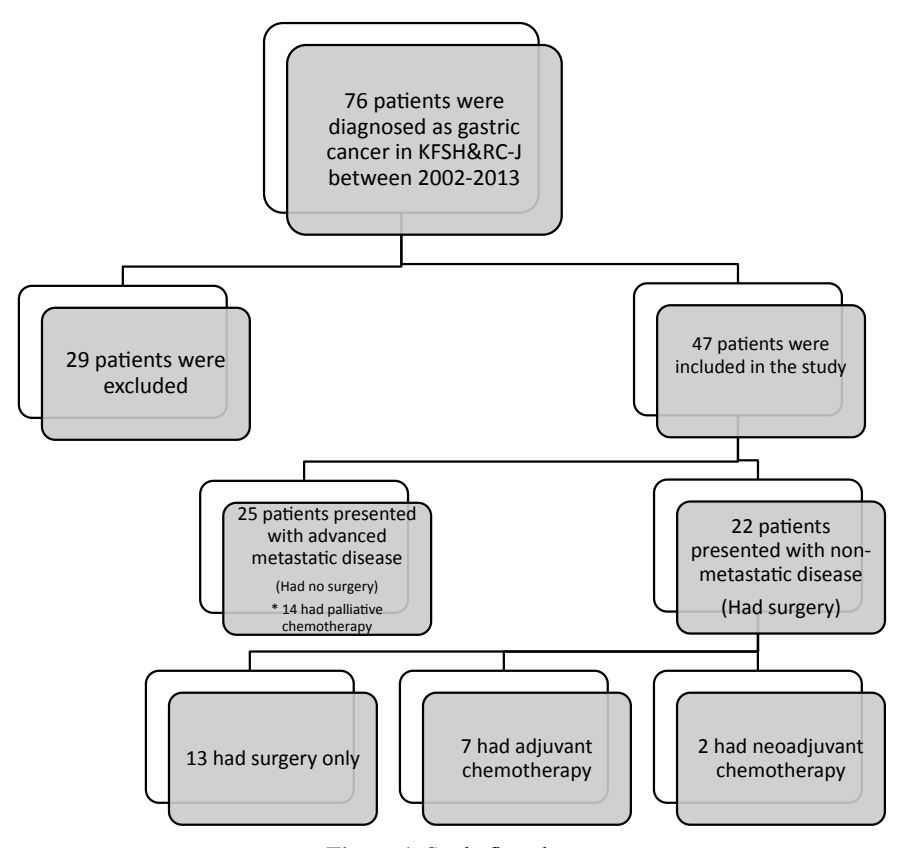

Figure 1. Study flowchart.

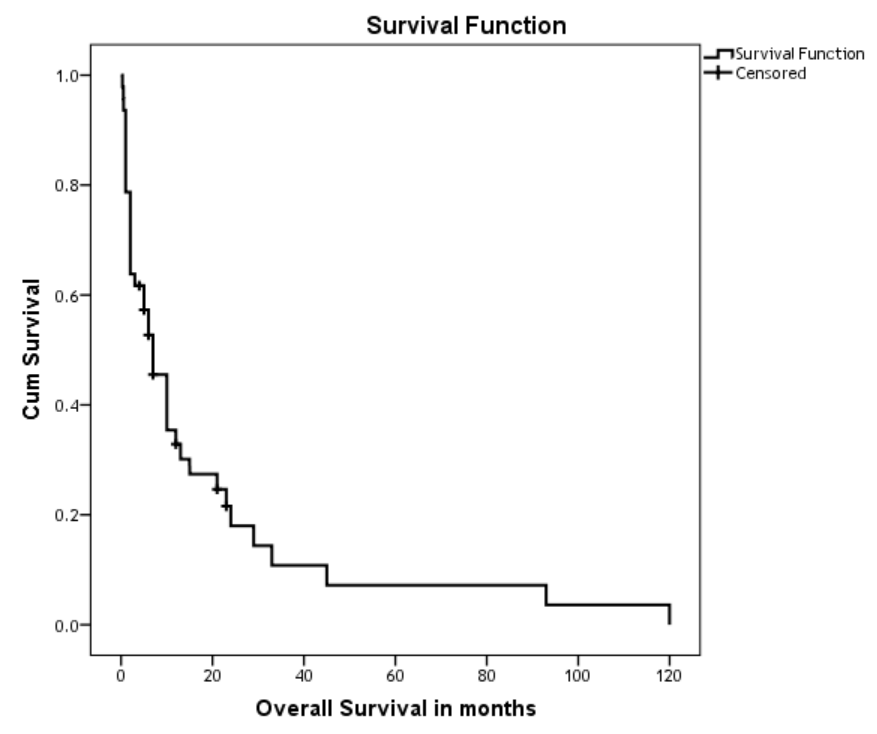

Figure 2. Kaplan-Meier curve shows the OS of Gastric Cancer Patients.

poorly differentiated tumors had higher $\mathrm{T} 4(\mathrm{n}=8,36.4 \%)$. On the other hand, those who had poorly differentiated tumors had higher $\mathrm{N} 1(\mathrm{n}=5$, $22.7 \%$ ), and those who had moderately differentiated had higher N3 $(\mathrm{n}=5,22.7 \%)$.

\section{Overall survivals and relapse free survivals}

The Overall Survival (OS) was recorded for all patients (47) in months. 40 patients died, the median estimate was 7 months $(95 \% \mathrm{CI}$ 3.67-10.32) (Figure 2). Disease-free survival was defined as the time from the day of surgery until the date of registration of recurrence. Disease Free Survival (DFS) was recorded for the 22 patients who underwent surgery (Figure 3). Fifteen out of the 22 who underwent surgery died. The median estimate was 24 months (95\%CI 9.15-38.84). Seven out of the $22 \mathrm{had}$ a recurrence. The disease free survival did not reach the median (Figure 3). The OS of the patients, who underwent surgery, was lower in those who had no adjuvant treatment, the median estimates in months for those who had ( $\mathrm{N}$ of events $=3$ ) and those who had no treatments ( $\mathrm{N}$ of events=12) were 29 vs. 21 (95\%CI 0-63.35 vs. $2.02-39.98)($ Log rank, $p$-value $=0.88)$. While the median estimate of the DFS for adjuvant therapy group ( $\mathrm{N}$ of events=1) did not reach the median, and the median estimates for those who had no adjuvant therapy ( $\mathrm{N}$ of events=6) was 24 month $(95 \mathrm{CI} \%$ 6.05-41.94) (Log rank, $\mathrm{p}$-value $=0.55$ ).

Those who had positive lympho-vascular invasion (LVI) (N of events $=9$ ) had lower OS compared to those who were negative ( $\mathrm{N}$ of events=6). The overall survival in months for positive and negative were 15 vs. 24 (95\%CI 0-34.66 vs. 99.85, respectively) (Log rank, $\mathrm{p}$-value $=0.1)$. The DFS estimates for the LVI positive $(\mathrm{N}$ of events $=3$ ) and negative ( $\mathrm{N}$ of events 4 ) didn't reach the median. (Log rank, p-value=0.7).

Those who had poorly differentiated adenocarcinoma ( $\mathrm{N}$ of events=6) the OS estimates in months were 29 versus 15 for the moderately differentiated adenocarcinoma ( $\mathrm{N}$ of events $=9)(95 \% \mathrm{CI}$ 18.64-39.35 vs. 3.27-26.72, respectively) (Log rank, p-value=0.1).The DFS estimates for both groups didn't reach the median ( $\mathrm{N}$ of events for moderately $=3$ and $n$ of events in poorly $=4)(\log$ rank, $p$-value $=0.3)$.

The OS in those who had signet ring feature ( $\mathrm{N}$ of events $=7$ ) was lower than those who did not have $(\mathrm{N}$ of events $=8$ ). The median estimate in months for the presence and absence of the signet ring feature were 15 vs. 29 (95\%CI 0-31.43 vs. 0-65.96, respectively) (Log rank, p-value $=0.12$ ). While the median estimate of the DFS ( $\mathrm{N}$ of events=3) in months for the presence of the signet ring feature was 24 (95\%CI $0-49.87$ ) and for the absence of this feature it didn't reach the median. (Log rank, p-value $=0.64)$.

\section{Discussion}

The National Cancer Registry of Saudi Arabia [13] revealed a total of 291 cases of stomach cancer diagnosed in 2010 in the Kingdom of Saudi Arabia according to the Saudi Cancer Registry data. This reflects a gradual increase in the incidence over the last decade in both male and female patients. Stomach cancer is the

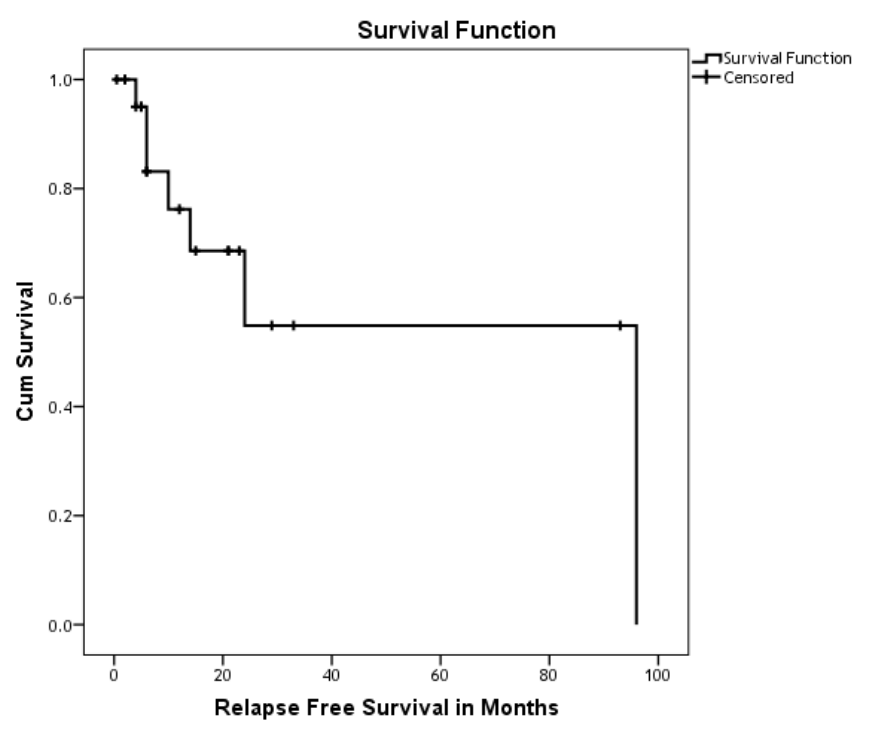

Figure 3. Kaplan-Meier curve shows the DFS for resectable gastric cancer. 
eleventh commonest cancer among the male and female populations. With 3.9\% incidence in males. It affected 165 (56.7\%) males and $126(43.3 \%)$ females with a male to female ratio of 131:100. The median age at diagnosis was 65 years for males (range 4-94 years), and 60 years for females (range 23-100 years). It account for $2.9 \%$ of all diagnosed cancers in Saudi Arabia. The overall ASR was 2.7/100,000. ASR was 3.1/100,000 for males and 2.3/100,000 for females. The five regions with the highest ASR were Najran region at 5.2/100,000, AlJouf region at 4.7/100,000, Riyadh region at 4.2/100,000, Eastern and Qassim regions at 3.2/100,000 for each [13].

In comparison of ASR for stomach cancer among Saudis with ASR in selected countries, it was one of the lowest. It was 2.3 for females and 3.1 for males while in Korea for example it was 26.7 for females and 64.2 for males, in the UK was 5.1 for females and 12.5 for males, and in USA was 4.6 for females and 9.2 for males [13]. 29.9\% of all patients presented with distant metastasis, while only $16.5 \%$ presented with localized disease, and $30.6 \%$ had regional disease [13]. There was a steady increase in the number of new cases diagnosed per year in Saudi Arabia since 1994. It was 130 new cases in males and 67 in females in 1994, and has increased to 165 in males and 126 in females in 2010 [13].

In the United States in 2015, the estimated number of new cases and deaths from gastric cancer were 24,590 and 10,720 respectively. The 5-year survival rate is only $29.3 \%$ in the years between $2005-2011$ [12]. While it varies from $10 \%$ to $55 \%$ worldwide [14]. $26.0 \%$ are diagnosed at a local stage. The 5-year survival for localized stomach cancer is $65.4 \%$ and (35\%) are diagnosed with distant metastasis [12].

Although gastric cancer is not one of the commonest cancers in Saudi Arabia, in our institution being a tertiary care hospital we get more referrals of gastric cancer cases more than other hospitals in the western region of Saudi Arabia. The total number of new cases is increasing gradually over the years as shown in Table 1 .

We believe that the relatively high mortality in our center can be attributed to the patients' late presentation in addition to the high lethal nature of the disease. The result of these factors must have resulted in a 7 months total median Overall Survival (OS) for all our patients (47). Forty patients of the 47 died, this high mortality is also due the late presentation since $60 \%$ of the (47) patients were stage four, while only $4 \%$ were stage 1.

Features of gastric cancer among our patients are comparable to those reported from high risk areas worldwide [14]. While the mean age of all patients at our institution was $57.55 \pm 19.24$ years, males $(70 \%)$ are more frequently affected than females. Intestinal type adenocarcinoma (91.5\%) is more common than diffuse type, (68.1\%) of which were poorly differentiated. For those who had poorly differentiated adenocarcinoma, the OS estimated in months was 29 versus 15 for the moderately differentiated adenocarcinoma. In the United States, the median age at diagnosis was 69 years, males were more commonly affected than females [12].

Lauren [15] has classified the gastric cancer into two types, the intestinal and diffuse types, which are two different biological types with different epidemiology, etiology, pathogenesis, and behavior. In the last few decades there has been a worldwide decline in the incidence of the intestinal type, while the decline in the diffuse type has been more gradual, which accounts approximately for $30 \%$ of the gastric cancer in some of the reported series [16].

A study by Adachi et al. [17], considered the histological type of gastric cancer (well differentiated and poorly differentiated) as one of the independent prognostic factors, withoverall 5-year survival rate for patients with well differentiated gastric cancer being higher than that for patients with poorly differentiated gastric cancer $(76 \% v s$. $67 \% ; \mathrm{P}=0.058$ ). There are four major histological patterns of gastric cancer recognized by the WHO classification of the year 2010: tubular, papillary, mucinous and poorly cohesive (including signet ring cell carcinoma), plus uncommon histologic variants [18]. Signet ring cell carcinoma and other poorly cohesive carcinomas tend to have lymphovascular invasion and lymph node metastasis if it occurs at the antro-pyloric region with serosal involvement [19].

In our study those who had signet ring features had higher N3 incidence $(\mathrm{n}=4,18.2 \%)$ and those who didn't have higher N1 incidence $(\mathrm{n}=4,18.2 \%)$. The prognosis of signet-ring cell adenocarcinoma is still debatable, in our study the OS in months for those who had signet ring feature (15) was lower than those who had not (29). Signet ring histology used to be considered as an independent predictor of worse prognosis in some of reported literature [20,21]. While some studies suggest that signet ring histology is associated with a more advanced stage of the disease at presentation, and doesn't portend a worse prognosis after adjustment of the stage [22-24].Surgery remains the mainstay of therapy for gastric cancer, with lymph node status being the most important prognostic factor [25]. While perioperative and adjuvant chemotherapy, as well as chemoradiation, can improve the outcome of resectable gastric cancer with extended lymph node dissection, neoadjuvant chemotherapy for gastric cancer aims for down-staging the disease and increases the chances of curative resection. Currently most guidelines recommend chemotherapy alone without radiotherapy (either as adjuvant treatment or combined preoperative and postoperative administration as in the multinational MAGIC trial [26]. In comparing the addition of chemotherapy or chemo-radiotherapy to surgery alone there was a survival benefit not obtained with adjuvant radiotherapy alone [27-30].

Currently centers in the United States have adopted the use of chemo-radiotherapy after resection as it showed survival benefit in the study done by a large American Intergroup trial (INT0116). Despite concerns that inadequate surgical staging (particularly the extent of lymphadenectomy) may have led to an overestimation of benefit [31].

As per the National Comprehensive Cancer Network (NCCN) guidelines for the treatment of stage IB to IIIC gastric cancer [32] in potentially resectable tumors, preoperative chemotherapy or chemoradiotherapy followed by surgery is appropriate, while patients who underwent D2 lymphadenectomy will receive postoperative chemoradiation or chemotherapy patients with unresectable tumors, treatment with fluoropyrimidine- or taxane-based chemoradiotherapy or chemotherapy is acceptable.

On the other hand The European Society for Medical Oncology/ European Society of Surgical Oncology/ European Society for Therapeutic Radiology and Oncology (ESMO-ESSO-ESTRO) recommendations for treatment of gastric cancer [33]: In general,the preferred treatment for operable gastric cancers beyond stage T1N0 is surgery with both preoperative and postoperative chemotherapy, and it is similar to NCCN guidelines for patients withstage IB disease or higher who do not receive preoperative chemotherapy. The treatment options include either chemoradiotherapy or chemotherapy in the adjuvant setting for medically fit patients, D2 lymph node dissection should be standard approach. While For inoperable or metastatic gastric cancer, treatment is with palliative chemotherapy, or best supportive care if the patient is unfit for treatment. 
HER2 gene and the role of monoclonal antibodies in the treatment of gastric cancer is still an area which need further research and assessment. In a reported Japanese series, HER2 overexpression in gastric cancer was $12 \%$ [34], while in other recent studies it is $22.1 \%$ [3537]. Human epithelial growth factor receptor 2 (HER2), is a member of the human epidermal growth factor receptor (EGFR) family with immunohistochemical stain. In a phase III international clinical trial called ToGA, it showed that combined chemotherapy (capocitabine or 5-fluorouracil and cisplatin), with humanized monoclonal antibody against HER2, Trastuzumab (Herceptin), could effectively prolong overall survival and progression-free survival, in HER2 positive advanced gastric carcinoma [36] and The European Society for Medical Oncology/ European Society of Surgical Oncology/ European Society for Therapeutic Radiology and Oncology (ESMO-ESSO-ESTRO) [33] recommended this treatment line too in patient with HER2 positive.

Our results showed that 15 out of the 22 patients who underwent surgery died. The survival median estimate was 24 months (95\%CI 9.15-38.84). Seven out of the 22 patients had recurrence. The OS of our patients, who underwent surgery, was lower in those who didn't have adjuvant treatment with the survival median estimates in months for those who had treatment and those who didn't was 29 vs. 21. In comparison to western countries more than half of radically resected gastric cancer patients relapse, either locally or with distant metastases [38].

The extent of lymphadenectomy in the treatment of gastric cancer is still widely controversial, but there is a general agreement that at least a D1 lymphadenectomy (namely lymph node stations from 1 to 7 according to the Japanese Gastric Cancer Association (JGCA) classification should be performed [39]. While the results of two European randomized trials carried out in the 1990s showed no survival benefit for D2 over D1 lymphadenectomy [40,41], and this was confirmed again with a recent meta-analysis which showed no significant differences in overall survival between D1 and D2, except in the group of patients who had D2 lymphadenectomy with splenectomy and/or pancreatectomy showed longer overall survival and a significant better disease-free survival rate [42]. Other eastern centers recommend D2 lymphadenectomy as part of the curative surgery as it significantly improves long-term results and overall survival rates [43]. In our study, 13 patients had D1 lymphadenectomy and 9 had D2 lymphadenectomy. The mean of the positive LN was $6.45 \pm 6.74$ and the mean of the total LN removed was $13.72 \pm 7.87$, and (31.8\%) had N3 staging.

\section{Conclusion}

Gastric cancer is among the deadliest forms of cancer in Saudi Arabia, surgery is the mainstay of curative treatment for resectable gastric cancer. More studies are required to look into the epidemiology and the pathology of gastric cancer in Saudi Arabia. As the prognosis of the disease remains poor in spite of all the advances achieved, even in those who had their resections done with a curative intent, this could be attributed to the high rates of recurrence, involved lymph nodes and systemic involvement. These together reveals the necessity for better and more effective adjuvant or neoadjuvant treatment. Therefore, in view of these facts, new perioperative, neoadjuvant, adjuvant and palliative chemotherapy strategies will be paramount for the treatment of these patients. Our study has described the general pattern of gastric cancer in a tertiary care hospital in the western region of Saudi Arabia with some of the features comparable to those seen in high risk populations worldwide. But there are still some differences that need to be further investigated considering the various geographical and demographical features of different provinces of the Kingdom of Saudi Arabia.

\section{Competing interests}

The authors declare that they have no competing interests.

\section{Acknowledgments}

We would like to thank Dr. Baker Binsadeq consultant epidemiologist and deputy director of the research center of the King Faisal Specialist Hospital Jeddah KSA for his appreciable efforts and help in reviewing the results of this manuscript and its statistical analysis.

\section{References}

1. "Chapter 1.1". World Cancer Report 2014. World Health Organization. 2014. ISBN 9283204298 .

2. Haenszel W (1958) Variation in incidence of and mortality from stomach cancer, with particular reference to the United States. J Natl Cancer Inst 21: 213-262. [Crossref]

3. Muñoz N, Asvall J. Time trends of intestinal and diffuse types of gastric cancer in Norway. Int J Cancer 1971; 8:144.

4. Hirayama T (1975) Epidemiology of cancer of the stomach with special reference to its recent decrease in Japan. Cancer Res 35(11 Pt. [Crossref]

5. Cancer incidence in five continents. Waterhouse J, Muir C, Correa P, et al (Eds), Vol III, IARC Scientific Publication no.15, International Agency for Research on Cancer, Lyon 1976

6. Zhu AL, Sonnenberg A (2012) Is gastric cancer again rising? J Clin Gastroenterol 46: 804-806. [Crossref]

7. Correa P (2011) Gastric cancer: two epidemics? Dig Dis Sci 56: 1585-1586. [Crossref]

8. GLOBOCAN, Cancer Incidence, Mortality and Prevalence Worldwide, IARC, Lyon: International Agency for Research on Cancer [Internet]. 2012 [accessed on 2015 Aug 22].

9. National Cancer Institute (2015) Gastric Cancer Treatment-for health professionals $\left(\mathrm{PDQ}{ }^{\circledR}\right)$.

10. Greenlee RT, Murray T, Bolden S, Wingo PA (2000) Cancer statistics, 2000. CA Cancer J Clin 50: 7-33. [Crossref]

11. Tamura S, Takeno A, Miki H (2011) Lymph node dissection in curative gastrectomy for advanced gastric cancer. Int J Surg Oncol 2011: 748745. [Crossref]

12. Surveillance, Epidemiology, and End Results Program. SEER Stat Fact Sheets: Stomach Cancer. National Cancer Institute

13. Saudi Cancer Registry (2014) Cancer Incidence Report in Saudi Arabia 2010. Riyadh (KSA): Saudi Cancer Registry.

14. Ferlay J, Shin HR, Bray F, Forman D, Mathers C, et al. (2010) Estimates of worldwide burden of cancer in 2008: GLOBOCAN 2008. Int J Cancer 127: 2893-2917. [Crossref]

15. Lauren P (1965) The Two Histological Main Types of Gastric Carcinoma: Diffuse and So-Called Intestinal-Type Carcinoma. An Attempt at a Histo-Clinical Classification. Acta Pathol Microbiol Scand 64:31-49. [Crossref]

16. Ikeda Y, Mori M, Kamakura T, Haraguchi Y, Saku M, et al. (1995) Improvements in diagnosis have changed the incidence of histological types in advanced gastric cancer. Br J Cancer 72: 424-426. [Crossref]

17. Adachi Y, Yasuda K, Inomata M, Sato K, Shiraishi N, et al. (2000) Pathology and prognosis of gastric carcinoma: well versus poorly differentiated type. Cancer 89: 1418-1424. [Crossref]

18. Lauwers GY, Carneiro F, Graham DY (2010) Gastric carcinoma. In: Bowman FT, Carneiro F, Hruban RH, eds. Classification of Tumours of the Digestive System. Lyon:IARC.

19. Bing Hu, Nassim El Hajj, Scott Sittler, et al. (2012) Gastric cancer: Classification, histology and application of molecular pathology. J Gastrointest Oncol 3: 251-261. [Crossref]

20. Piessen G, Messager M, Leteurtre E, Jean-Pierre T, Mariette C (2009) Signet ring cell histology is an independent predictor of poor prognosis in gastric adenocarcinoma regardless of tumoral clinical presentation. Ann Surg 250: 878-887. [Crossref] 
21. Ribeiro MM, Sarmento JA, Sobrinho Simões MA, Bastos J (1981) Prognostic significance of Lauren and Ming classifications and other pathologic parameters in gastric carcinoma. Cancer 47: 780. [Crossref]

22. Kim DY, Park YK, Joo JK, Ryu SY, Kim YJ, et al. (2004) Clinicopathological characteristics of signet ring cell carcinoma of the stomach. ANZ J Surg 74: 10601064. [Crossref]

23. Taghavi S, Jayarajan SN, Davey A, Willis AI (2012) Prognostic significance of signet ring gastric cancer. J Clin Oncol 30: 3493-3498. [Crossref]

24. Bamboat ZM, Tang LH, Vinuela E, Kuk D, Gonen M, et al. (2014) Stage-stratified prognosis of signet ring cell histology in patients undergoing curative resection for gastric adenocarcinoma. Ann Surg Oncol 21: 1678-1685. [Crossref]

25. Edge SB, Compton CC (2010) The American Joint Committee on Cancer: the 7th edition of the AJCC cancer staging manual and the future of TNM. Ann Surg Oncol 17: 1471-1474. [Crossref]

26. Cunningham D, Allum WH, Stenning SP, Thompson JN, Van de Velde CJ, et al. (2006) Perioperative chemotherapy versus surgery alone for resectable gastroesophageal cancer. N Engl J Med 355: 11-20. [Crossref]

27. Ko KJ, Shim JH, Yoo HM, O SI, Jeon HM, et al. (2012) The clinical value of noncurative resection followed by chemotherapy for incurable gastric cancer. World $J$ Surg 36: 1800-1805. [Crossref]

28. Hallissey MT, Dunn JA, Ward LC, Allum WH (1994) The second British Stomach Cancer Group trial of adjuvant radiotherapy or chemotherapy in resectable gastric cancer: five-year follow-up. Lancet 343: 1309-1312. [Crossref]

29. [No authors listed] (1982) A comparison of combination chemotherapy and combined modality therapy for locally advanced gastric carcinoma. Gastrointestinal Tumor Study Group. Cancer 49: 1771-1777. [Crossref]

30. Schwarz RE, Zagala-Nevarez K (2002) Recurrence patterns after radical gastrectomy for gastric cancer: prognostic factors and implications for postoperative adjuvan therapy. Ann Surg Oncol 9: 394-400. [Crossref]

31. Macdonald JS, Smalley SR, Benedetti J, et al. (2001) Chemoradiotherapy after surgery compared with surgery alone for adenocarcinoma of the stomach or gastroesophageal junction. $N$ Engl J Med 345:725. [Crossref]

32. National Comprehensive Cancer Network. Gastric Cancer: Version 3.2015. NCCN.

33. Waddell T, Verheij M, Allum W, Cunningham D, Cervantes A, et al. (2013) Gastric cancer: ESMO-ESSO-ESTRO Clinical Practice Guidelines for diagnosis, treatment and follow-up. Ann Oncol 24 Suppl 6: vi57-63. [Crossref]

34. Yonemura Y, Ninomiya I, Yamaguchi A, Fushida S, Kimura H, et al. (1991) Evaluation of immunoreactivity for erbB-2 protein as a marker of poor short term prognosis in gastric cancer. Cancer Res 51: 1034-1038. [Crossref]

35. Yokota J, Yamamoto T, Toyoshima K, Terada M, Sugimura T, et al. (1986) Amplification of c-erbB-2 oncogene in human adenocarcinomas in vivo. Lancet 1 : 765-767. [Crossref]

36. Van Cutsem E, Kang Y, Chung H (2009) Efficacy results from the ToGA trial: A phase III study of trastuzumab added to standard chemotherapy (CT) in first-line human epidermal growth factor receptor 2 (HER2)-positive advanced gastric cancer (GC). $J$ Clin Oncol 27: LBA 4509.

37. Bang YJ, Van Cutsem E, Feyereislova A, Chung HC, Shen L, et al. (2010) Trastuzumab in combination with chemotherapy versus chemotherapy alone for treatment of HER2positive advanced gastric or gastro-oesophageal junction cancer (ToGA): a phase 3 , open-label, randomised controlled trial. Lancet 376: 687-697. [Crossref]

38. Orditura M, Galizia G, Sforza V, Gambardella V, Fabozzi A, et al. (2014) Treatment of gastric cancer. World J Gastroenterol 20: 1635-1649. [Crossref]

39. Japanese Gastric Cancer Association (2011) Japanese classification of gastric carcinoma: 3rd English edition. Gastric Cancer 14: 101-112. [Crossref]

40. Bonenkamp JJ, Songun I, Hermans J, Sasako M, Welvaart K, et al. (1995) Randomised comparison of morbidity after D1 and D2 dissection for gastric cancer in 996 Dutch patients. Lancet 345: 745-748. [Crossref]

41. Cuschieri A, Fayers P, Fielding J, Craven J, Bancewicz J, Joypaul V, Cook P (1996) Postoperative morbidity and mortality after D1 and D2 resections for gastric cancer: preliminary results of the MRC randomised controlled surgical trial. The Surgical Cooperative Group. Lancet 347: 995-999. [Crossref]

42. Jiang L, Yang KH, Guan QL, Zhao P, Chen Y, et al. (2013) Survival and recurrence free benefits with different lymphadenectomy for resectable gastric cancer: a metaanalysis. J Surg Oncol 107: 807-814. [Crossref]

43. Jiang L, Yang KH, Guan QL, Zhao P, Chen Y, et al. (2013) Survival and recurrence free benefits with different lymphadenectomy for resectable gastric cancer: a metaanalysis. J Surg Oncol 107: 807-814. [Crossref]

44. Japanese Gastric Cancer Association (2011) Japanese gastric cancer treatment guidelines 2010 (ver. 3). Gastric Cancer 14: 113-123. [Crossref]

Copyright: (C2016 Raha A. This is an open-access article distributed under the terms of the Creative Commons Attribution License, which permits unrestricted use, distribution, and reproduction in any medium, provided the original author and source are credited. 